\title{
Physicochemical and Descriptive Sensory Analysis of Arkansas-grown Peaches and Nectarines
}

\author{
Molly Felts and Renee T. Threlfall ${ }^{1}$ \\ Department of Food Science and Institute of Food Science and Engineering, \\ University of Arkansas, 2650 North Young Avenue, Fayetteville, AR 72704
}

\author{
Margaret L. Worthington \\ Department of Horticulture, 316 Plant Science, University of Arkansas, \\ Fayetteville, AR 72701
}

Additional index words. Prunus persica, composition, firmness, ripeness

\begin{abstract}
Understanding how human perception is related to physicochemical attributes strengthens identification of ripeness and marketability parameters for peaches and nectarines [Prunus persica (L.) Batsch]. Six peach and nectarine cultivars (Amoore Sweet, Bowden, Effie, Loring, Souvenirs, and White River) and three advanced breeding selections (A-827, A-850, and A-865) were harvested from trees grown at the University of Arkansas System Division of Agriculture Fruit Breeding Program in Clarksville, AR. Physical and chemical characteristics of the genotypes at harvest were as follows: fruit weight of 134.4 to $330.2 \mathrm{~g}$, firmness of 7.8 to $35.8 \mathrm{~N}$, soluble solids of $7.5 \%$ to $14.7 \%$, pH of 3.3 to 4.8 , titratable acidity of $0.2 \%$ to $1.1 \%$, total sugars of 1.7 to $10.4 \mathrm{~g} / 100 \mathrm{~g}$, and total organic acids of 0.1 to $0.9 \mathrm{~g} / 100 \mathrm{~g}$. Overall, $\mathrm{A}-865 \mathrm{had}$ the lowest fruit weight $(134.0 \mathrm{~g})$ and pH (3.3), and the highest firmness $(35.8 \mathrm{~N})$, soluble solids $(14.7 \%)$, titratable acidity $(1.1 \%)$, total sugars $(10.4 \mathrm{~g} / 100 \mathrm{~g})$, and total organic acids $(0.8 \mathrm{~g} / 100 \mathrm{~g})$. 'White River' had the largest fruit (330.2 g) and pit (11.06 g). A-850 (63.6) had the highest soluble solids/ titratable acidity ratio, and 'Bowden' (12.7) had the lowest. A trained descriptive sensory panel $(n=10)$ was used to create a lexicon for Arkansas-grown fresh-market peaches and nectarines. The panel evaluated the fruit for aroma $(n=4)$, external appearance $(n=8)$, internal appearance and pit attributes $(n=6)$, basic tastes $(n=3)$, aromatics while eating fruit $(n=5)$, feeling factors $(n=2)$, and texture $(n=6)$. Principal component analysis explained $63.4 \%$ of the data variance attributed to texture and acidity. Of all of the physicochemical attributes, firmness had the most significant correlations with the descriptive sensory attributes, followed by fruit weight. Firmness was negatively correlated $(r=-0.70$ to 0.81$)$ to fruit size, fuzziness, amount of bruises on the flesh, pit size, and moisture release, and positively correlated $(r=0.68-0.84)$ to sourness, green/ unripe aromatics, flesh hardness, flesh crispness, and fibrousness between the teeth. Fruit weight was positively correlated $(r=0.67-0.75)$ to fruit and pit size, overripe aromatics, and moisture release. Significant correlations between descriptive sensory appearance, basic tastes, aromatics, and texture attributes with physicochemical attributes provide an indication of ripeness and marketability parameters for peaches and nectarines. These descriptive attributes are quality factors that impact consumer purchases and perception of fresh-market peaches and nectarines.
\end{abstract}

Peaches (Prunus persica L. Batsch) have been cultivated worldwide for thousands of years. Peaches and nectarines belong to the same species but are differentiated by a single genetic locus that controls pubescence. Peaches and nectarines are both climacteric fruit (ripen after harvest) and have different types of flesh (mesocarp). The flesh types,

\footnotetext{
Received for publication 20 June 2018. Accepted for publication 17 Dec. 2018.

This research was funded by the Specialty Crop Block Grant from the Arkansas Agriculture Department, U.S. Department of Agriculture (16SCBGPAR0038) and U.S. Department of Agriculture-National Institute of Food and Agriculture Hatch funds for "Breeding Peaches and Nectarines Adapted to the Soils and Climate of Arkansas" (Project Number ARK02402).

${ }^{1}$ Corresponding author. E-mail: rthrelf@uark.edu.
}

vars; however, there are no freestone nonmelting flesh peaches, as pit adherence and flesh type are controlled by allelic variation at the same genetic locus (Ramina et al., 2008). Finally, other attributes of the fruit differ, such as the base color of the mesocarp, the acidity of the flesh, and the shape. The most common flesh colors are white and yellow, and the exterior of the fruit can have a blush (red hue), which sometimes continues into the flesh near the pit or skin. The most common peach and nectarine shape in the United States is round (or oblong shaped), although flat-shaped fruit also are found.

All of these attributes of peaches and nectarines affect how consumers perceive quality. Sensory methods, such as descriptive sensory analysis, are important to determine how physicochemical attributes are perceived when evaluated by a human subject (Contador et al., 2017). Previous sensory studies on peaches indicated attributes such as appearance, aroma, flavor, sweetness, sourness, and texture were common indicators of consumer acceptability of peaches, and primary drivers of liking include sweetness perception, grassy green fruit, and pit aromas (Belisle et al., 2017; Delgado et al., 2013). Descriptive sensory analysis was effective for identification of texture differences in both melting and nonmelting flesh peaches grown in California, as well as for soluble solids/titratable acidity ratios (Crisosto and Crisosto, 2005). Descriptive sensory analysis provides a means of quantitatively scaling attributes of food, whereas consumer sensory analysis demonstrates a degree of liking or preference from consumers. Delgado et al. (2013) evaluated "in-store" consumer $(\mathrm{n}=120)$ acceptability descriptive sensory $(n=11)$ of seven nectarine and peach cultivars and found sensory attribute measurements explained cultivar characteristics better than instrumental measures alone.

Although California is the largest U.S. producer of peaches and nectarines, peach production in Arkansas was $\approx 820 \mathrm{t}$ in 2014 (USDA, 2015). In the late 19th century, Arkansas had a significant industry growing and processing peaches to diversify farm operations. Thus, when the University of Arkansas Peach Breeding Program (Fruit Research Station, Clarksville, AR) began in the mid-1960s, the initial breeding focus was on the development of clingstone peaches for processing for the baby food industry (Worthington and Clark, 2019). The breeding program shifted focus in the 1990s toward fresh-market fruit because of a decline in the processing peach industry in Arkansas (Worthington and Clark, 2019). Since the start of this breeding program, 12 peach and six nectarine cultivars have been released. Current breeding selection criteria at the University of Arkansas include firm fruit with different flavors, acidity, and sweetness, as well as tree characteristics, such as time of ripening, disease resistance, and productivity. The program currently has many advanced peach and nectarine selections, with 
melting and nonmelting flesh, as well as white and yellow color, varying levels of blush and acidity, ranges of ripening dates, size, and both round and flat shapes.

The objective of this study was to evaluate how descriptive sensory attributes were related to physicochemical attributes of fresh-market Arkansas-grown peaches and nectarines. It was hypothesized that relevant correlations between analytical and descriptive sensory methods would be identified; therefore, expanding the understanding of how attributes of peaches and nectarines are perceived. There were limitations to this project, as the fruit evaluated included both Arkansas-grown peaches and nectarines with different acidity levels (low, medium, and high), stone types (freestone and clingstone), flesh textures (nonmelting, slow-melting, and melting), and flesh colors (yellow and white).

\section{Materials and Methods}

\section{Plants and culture}

Nine peach and nectarine genotypes (cultivars and advanced breeding selections) were evaluated (Table 1). Five peaches (A827, A-850, 'Loring', 'Souvenirs', and 'White River') and four nectarines (A-865, 'Amoore Sweet', 'Bowden', and 'Effie') were evaluated in this study. The fruit was harvested from trees grown at the University of Arkansas Fruit Research Station, Clarksville, AR [west-central Arkansas, lat. $35^{\circ} 31^{\prime} 58^{\prime \prime} \mathrm{N}$ and long. $93^{\circ} 24^{\prime} 12^{\prime \prime} \mathrm{W}$; USDA hardiness zone $7 \mathrm{a}$; soil type Linker fine sandy loam (Typic Hapludult)]. Fruit was harvested from trees ranging from 4 to 10 years old that were either open-center trained and spaced $5.5 \mathrm{~m}$ between trees and rows, or trained to a perpendicular- $\mathrm{V}$ system with trees spaced $1.9 \mathrm{~m}$ in rows spaced $5.5 \mathrm{~m}$ apart. No bactericides were applied to plantings during testing. Insect pests and fungal pathogens were controlled following recommendations in the southeastern peach, nectarine, and plum pest management and culture guide (Blaauw et al., 2018). Based on recommendations from soil tests performed by the University of Arkansas System Division of Agriculture (Fayetteville, AR), trees were fertilized annually with a split application of $\mathrm{N}$ fertilizer in early March and late April or early May. Other macronutrients, including $\mathrm{P}$ and $\mathrm{K}$, were applied with $\mathrm{N}$ during the early March application, as recommended by soil tests. The quantity of nutrients applied varied across years depending on the age of each tree and the results of soil testing. All trees were dormant-pruned annually and thinned to a distance of 12 to $15 \mathrm{~cm}$ fruit between shuck split and pit hardening.

\section{Harvest}

The peaches and nectarines were hand harvested in the morning (between 7:00 and 10:00 AM) on two harvest dates (27 June and 11 July 2017) at optimal ripeness (a slight softening at the suture and absence of green ground color) and were free of major blemishes, flaws, or damage. 'Amoore Sweet', 'Bowden', 'Effie', 'Souvenirs', and A-865

Table 1. Genotypic traits of fresh-market peach and nectarine genotypes, Clarksville, AR (2017).

\begin{tabular}{llllll}
\hline Genotype & Fruit type & Stone type & Flesh type & Flesh color & Acidity \\
\hline A-827 & Peach & Freestone & Slow-melting & Yellow & Low \\
A-850 & Peach & Freestone & Melting & White & Low \\
A-865 & Nectarine & Freestone & Slow-melting & White & High \\
Amoore Sweet & Nectarine & Clingstone & Nonmelting & Yellow & Low \\
Bowden & Nectarine & Clingstone & Nonmelting & White & High \\
Effie & Nectarine & Clingstone & Nonmelting & White & Medium \\
Loring & Peach & Freestone & Melting & Yellow & High \\
Souvenirs & Peach & Freestone & Slow-melting & Yellow & Low \\
White River & Peach & Freestone & Melting & White & High \\
\hline
\end{tabular}

were harvested on 27 June, and 'Loring', 'White River', A-827, and A-850 were harvested on 11 July. There were no rain events within $24 \mathrm{~h}$ of either harvest. Approximately 54 peaches and nectarines were harvested for each genotype and placed into three boxes that contained corrugated pulp trays with individual wells for each fruit. Extra fruit was harvested in case there was damage or decay to the fruit during or after harvest. The boxes of fruit were transported in an airconditioned vehicle to the University of Arkansas, Department of Food Science, in Fayetteville, AR. The fruit was randomly placed into new pulp trays. The randomization of the fruit after harvest was done to minimize the differences in fruit quality that might have been caused by tree canopy position or maturity states. The fruit was evaluated for descriptive sensory and physicochemical attributes at harvest.

\section{Physicochemical analysis}

Fruit for physicochemical analysis was done in triplicate per genotype. Each experimental unit was an individual peach or nectarine. The physicochemical analysis included physical attributes, color, and composition evaluated at harvest. On the day of harvest, the fruit was weighed, the exterior color was measured, the firmness was measured, and then the fruit was cut in half for interior color and pit size. The other half of each fruit was frozen at $-10{ }^{\circ} \mathrm{C}$ for composition.

Physical. The physical attributes were evaluated on the day of harvest. Fruit and pit weight were measured on a digital scale (PA224 Analytic Balance; Ohaus Corporation, Parsippany, NJ). Fruit weight was the weight of a whole, intact peach or nectarine. Pit weight was evaluated on the pit extracted from the fruit. Firmness of the fruit flesh was measured using a Stable Micro Systems TA. XT.plus Texture Analyzer (Texture Technologies Corporation, Hamilton, MA). Before the firmness measurement, three sections of skin per fruit were removed by slicing off a 5$\mathrm{mm}$ section at the firmness measurement site. The fruit was then placed on a flat surface. Using the 2-mm-diameter probe, at a rate of $2 \mathrm{~mm} \cdot \mathrm{s}^{-1}$ with a trigger force of $0.02 \mathrm{~N}$, firmness of the fruit flesh was evaluated at three locations per fruit $\left(90^{\circ}, 180^{\circ}\right.$, and $270^{\circ}$ to the right of the suture). Force to penetrate the fruit was measured in Newtons $(\mathrm{N})$.

Color. The color of the fruit skin and flesh was analyzed on the day of harvest using a Konica Minolta CR-400 Chroma Meter
(Konica Minolta, Inc., Ramsey, NJ). The $\mathrm{L}^{*}$, chroma, and hue angle were evaluated. Color analysis was done to determine Commission Internationale de 1'Eclairage (CIE) Laboratory transmission values of $\mathrm{L}^{*}=100$, $\mathrm{a}^{*}=0$, and $\mathrm{b}^{*}=0$ (CIE, 1986). The CIELAB system describes color variations as perceived by the human eye. CIELAB is a uniform three-dimensional space defined by colorimetric coordinates, $\mathrm{L}^{*}, \mathrm{a}^{*}$, and $\mathrm{b}^{*}$. The vertical axis $L^{*}$ measures lightness from completely opaque (0) to completely transparent (100), whereas on the hue-circle, $+\mathrm{a}^{*}$ red, $-\mathrm{a}^{*}$ green, $+\mathrm{b}^{*}$ yellow, and $-\mathrm{b}^{*}$ blue were measured. Hue angle, calculated as $\arctan \left(\mathrm{b}^{*} / \mathrm{a}^{*}\right)$, described color in angles from 0 to $360^{\circ}\left(0^{\circ}\right.$ is red, $90^{\circ}$ is yellow, $180^{\circ}$ is green, $270^{\circ}$ is blue, and $360^{\circ}$ is red). Chroma, calculated as $\left[\left(a^{*}\right)^{2}+\left(b^{*}\right)^{2}\right]^{0.5}$, identified color by which a sample appears to differ from gray of the same lightness and corresponds to intensity of the perceived color. Skin color was evaluated on three locations for each fruit $\left(90^{\circ}, 180^{\circ}\right.$, and $270^{\circ}$ to the right of the suture). The fruit was then cut in half and the fruit flesh was immediately analyzed for color in three locations similar to how the exterior color was measured.

Composition. After physical and color attributes were evaluated, the fruit was frozen at $-10{ }^{\circ} \mathrm{C}$ for composition. The fruit half was thawed for composition analysis (soluble solids, $\mathrm{pH}$, titratable acidity, organic acids, and sugars). Each fruit half (skin and flesh) per genotype and replication was macerated in a Magic Bullet for $2 \mathrm{~min}$ (Homeland Housewares, Los Angeles, CA), then the juice was centrifuged at $5000 \mathrm{rpm}$ for $8 \mathrm{~min}$ and strained through cheese cloth. The $\mathrm{pH}$ and titratable acidity of the fruit were measured using the Titrino Plus 862 Compact Titrosampler (Metrohm AG, Herisan, Switzerland) with the electrode standardized to $\mathrm{pH} 4.00,7.00$, and 10.00 buffers. Titratable acidity was determined using $\approx 6 \mathrm{~g}$ of juice diluted with $50 \mathrm{~mL}$ deionized, degassed water with a titration using $0.1 \mathrm{~N}$ sodium hydroxide to an endpoint of $\mathrm{pH}$ 8.2. Titratable acidity was expressed as percentage of malic acid. Soluble solids (expressed as percent) of the fruit was measured using an Abbe Mark II refractometer (Bausch and Lomb, Scientific Instrument, Keene, NH). Organic acids and sugars of the fruit were determined using high-performance liquid chromatography (HPLC). The juice from compositional analysis was then filtered through a $0.45-\mu \mathrm{m}$ nylon filter (VWR International, Radnor, PA) for HPLC analysis. 
Glucose, fructose, isocitric acid, and malic acid of the fruit were measured using previously established HPLC procedures (Segantini et al., 2018; Walker et al., 2003). The HPLC was equipped with a Bio-Rad HPLC Organic Acid Analysis Aminex HPX$87 \mathrm{H}$ ion exclusion column $(300 \times 7.8 \mathrm{~mm})$, Bio-Rad HPLC Fast Acid Analysis column $(100 \times 7.8 \mathrm{~mm})$, and a Bio-Rad HPLC column for fermentation monitoring $(150 \times$ $7.8 \mathrm{~mm}$ ) in series (Bio-Rad, Hercules, CA). A Bio-Rad Micro-Guard Cation-H refill cartridge $(30 \times 4.5 \mathrm{~mm})$ was used for a guard column. Columns were maintained at $65{ }^{\circ} \mathrm{C}$ by a temperature control unit. Mobile phase consisted of a $\mathrm{pH} 2.28$ solution of sulfuric acid and water with a resistivity of $18 \mathrm{M}$ obtained from a Millipore Milli-Q reagent water system. The sulfuric acid solution was used as the solvent with $0.45 \mathrm{~mL} \cdot \mathrm{min}^{-1}$ flow rate. The solvent delivery system was a Waters 515 HPLC pump equipped with a Waters 717 Plus autosampler (Waters Corporation, Milford, MA). Injection volumes were $10 \mu \mathrm{L}$ for all samples, and run time for completion was $35 \mathrm{~min}$. A Waters 410 differential refractometer to measure refractive index connected in series with a Waters 996 photodiode array detector monitored the eluting compounds. Isocitric and malic acids were detected by photodiode array at $210 \mathrm{~nm}$, and glucose and fructose were detected by the differential refractometer. The peaks were quantified using external standard calibration based on peak height estimation with baseline integration. Individual sugars and acids, total sugars (glucose + fructose), and total organic acids (isocitric + malic) were expressed as $\mathrm{g} / 100 \mathrm{~g}$.

\section{Descriptive sensory evaluation}

Descriptive sensory analysis was performed at the Sensory and Consumer Research Center at the University of Arkansas, Fayetteville, AR. The 10 descriptive panelists (two male and eight female ages 35-75) who evaluated the peaches and nectarines had more than 10 years of experience descriptively evaluating products for the Sensory and Consumer Research Center. The panelists were trained to use a modified Sensory Spectrum method, an objective method for describing the intensity of attributes in products using references for the attributes. The descriptive panelists developed a lexicon of sensory attributes for the peaches and nectarines through consensus during orientation and practice sessions (two sessions) (Table 2).

After harvest, the fruit for sensory evaluation was stored overnight at $2{ }^{\circ} \mathrm{C}$ with $85 \%$ to $89 \%$ relative humidity, then removed from cold storage, gently rinsed, placed on pulp trays, and allowed to air-dry. Each panelist evaluated one fruit for each genotype in duplicate. The fruit was served monadically (one at a time) at room temperature $\left(25^{\circ} \mathrm{C}\right.$ ) on plates labeled with three-digit codes in a randomized complete block design. Panelists were instructed to cleanse their palates with unsalted crackers and water between sam- ples. Expectorant cups were also provided. Serving order was randomized across each replication and panelist to prevent presentation order bias. The descriptive panel evaluated the fruit for aroma $(n=4)$, external appearance $(\mathrm{n}=8)$, internal appearance and pit attributes $(n=6)$, basic tastes $(n=3)$, aromatics while eating $(n=5)$, feeling factors $(n=2)$, and texture $(n=6)$. The panelists first evaluated the aroma and exterior attributes of whole, intact fruit. After evaluating the aroma and exterior attributes of the fruit, the panelists were instructed to cut the peach/nectarine in half with a knife, then slice the half without the pit into four slices (one-eighth of the whole). The half of the fruit with the pit was used for the evaluation of internal and pit attributes. The four slices from the half of the fruit without the pit were used for basic tastes, aromatics, feeling factors, and texture. The fruit attributes were evaluated using a 15-point scale in which $0=$ less of an attribute and $15=$ more of an attribute.

\section{Design and statistical analysis}

Three individual fruit per genotype were used for physicochemical analysis (three replications, completely randomized design), and the descriptive sensory analysis was organized as a randomized complete block design with two replicates. Individual fruit were the experimental units in both physicochemical and descriptive sensory analyses. For physicochemical data, a univariate analysis of variance (ANOVA) was used to determine the significance of the main factor (genotype) using Tukey's honestly significant difference test to detect significant differences $(P<0.05)$ among means. For descriptive sensory analysis, a mixed model ANOVA was performed with genotype considered a fixed factor and panelist, replication, and genotype $\times$ panelist interaction considered random effects. Means separation was performed with Fisher's protected least significant difference to detect significant differences $(P<0.05)$ among genotypes. Pairwise correlations using multivariate analysis were used to verify the relationship between/within attributes $(P<0.05)$, and multivariate analysis was used to determine principal component analysis.

\section{Results and Discussion}

\section{Physicochemical attributes at harvest}

The nine peach and nectarine genotypes were evaluated for physicochemical attributes (physical, color, and composition). Physicochemical attributes were significant for all attributes for the genotypes evaluated (Table 3). 'White River' (330.20 g) was the largest fruit, and A-865 (134.40 g) and 'Amoore Sweet' (137.46 g) were the smallest. 'White River' was larger than previously reported, with a 10- to 14-year fruit weight of $201 \mathrm{~g}$ (Clark and Moore, 2003). A study by Rahmati et al. (2015) indicated that when drought stress is high, fruit weight is negatively affected. The 2017 harvest was an exceptionally wet year in Arkansas, with $455 \mathrm{~mm}$ of rain from April to June, which could have contributed to the increased fruit weight. In addition, thinning practices may have had an effect on fruit size. 'White River' $(11.06 \mathrm{~g})$ also had the largest pit, and 'Amoore Sweet' (4.62 g) had the smallest. There was a significant difference in firmness among genotypes, with A-865, a freestone, slow-melting nectarine $(35.81 \mathrm{~N})$ having the highest firmness and A-827, a freestone, slow-melting peach $(7.77 \mathrm{~N})$ the lowest.

The color of the skin and flesh of the fruit were evaluated (Table 4). L* and chroma of the skin and flesh were significant for these genotypes, but for the flesh, the hue value was significant. For fruit skin, 'White River' (65.52) had the highest $L^{*}$ value, and 'Souvenirs' (38.38) had the lowest. 'Amoore Sweet' (52.23) had the highest skin chroma value, and A-865 (31.73) had the lowest. There was no difference among genotypes for skin hue, which ranged from 30.74 to 57.51. For flesh $\mathrm{L}^{*}$ value, A-850, a whitefleshed peach, had the highest value, and 'Souvenirs', a yellow-fleshed peach, the lowest. McGuire (1992) stated that hue angle can be useful in identification of ripeness as fruit ripen from green to either yellow or shades of red. A hue angle from 45 to $90^{\circ}$ is orange to yellow and 90 to $180^{\circ}$ is yellow to green. The flesh hue angle ranged from 56.52 to 99.89 . Hue angle can be used for identification of ground color as a determination of ripeness (Shinya et al., 2013). A-850, A-865, 'Bowden', 'Effie', and 'White River' were whitefleshed, and A-827, 'Amoore Sweet', 'Loring', and 'Souvenirs' were yellow-fleshed. 'Amoore Sweet' (49.68) had the highest flesh chroma, and A-850 (16.27) had the lowest. Bible and Singha (1993) indicated fruit from the upper canopy could have higher chroma values and increasing redness indicated by a lower hue angle as compared with fruit found in the lower canopy. As the fruit in this study was randomly taken from all locations on the tree, variations in chroma and hue due to fruit location within a genotype were possible. The $\mathrm{L}^{*}$ values of the flesh and skin of the peaches and nectarines were in the midrange between opaque (0) and transparent (100). The $\mathrm{L}^{*}$ value of the skin of each genotype tended to be lower than the $\mathrm{L}^{*}$ value of the flesh. In general, the hue of the flesh and skin of the peaches and nectarines was between $0^{\circ}$ (red) and $90^{\circ}$ (yellow), with the flesh having a trend for higher (more yellow) values than the skin. There were not trends with chroma values for these genotypes.

The composition attributes measured included soluble solids, $\mathrm{pH}$, titratable acidity, organic acids, and sugars (Table 3). A-865 $(14.70 \%)$ had the highest soluble solids, and 'Loring' $(7.50 \%)$ had the lowest. A-850 (4.79) had the highest $\mathrm{pH}$, and A-865 (3.30) had the lowest. Titratable acidity had an inverse relationship to $\mathrm{pH}$, in which A- 850 $(0.16 \%)$ had the lowest titratable acidity, and A-865 (1.07\%) had the highest. A-850 is a low acid fruit, whereas A-865 is a high acid fruit. Crisosto (1994) established stone fruit 


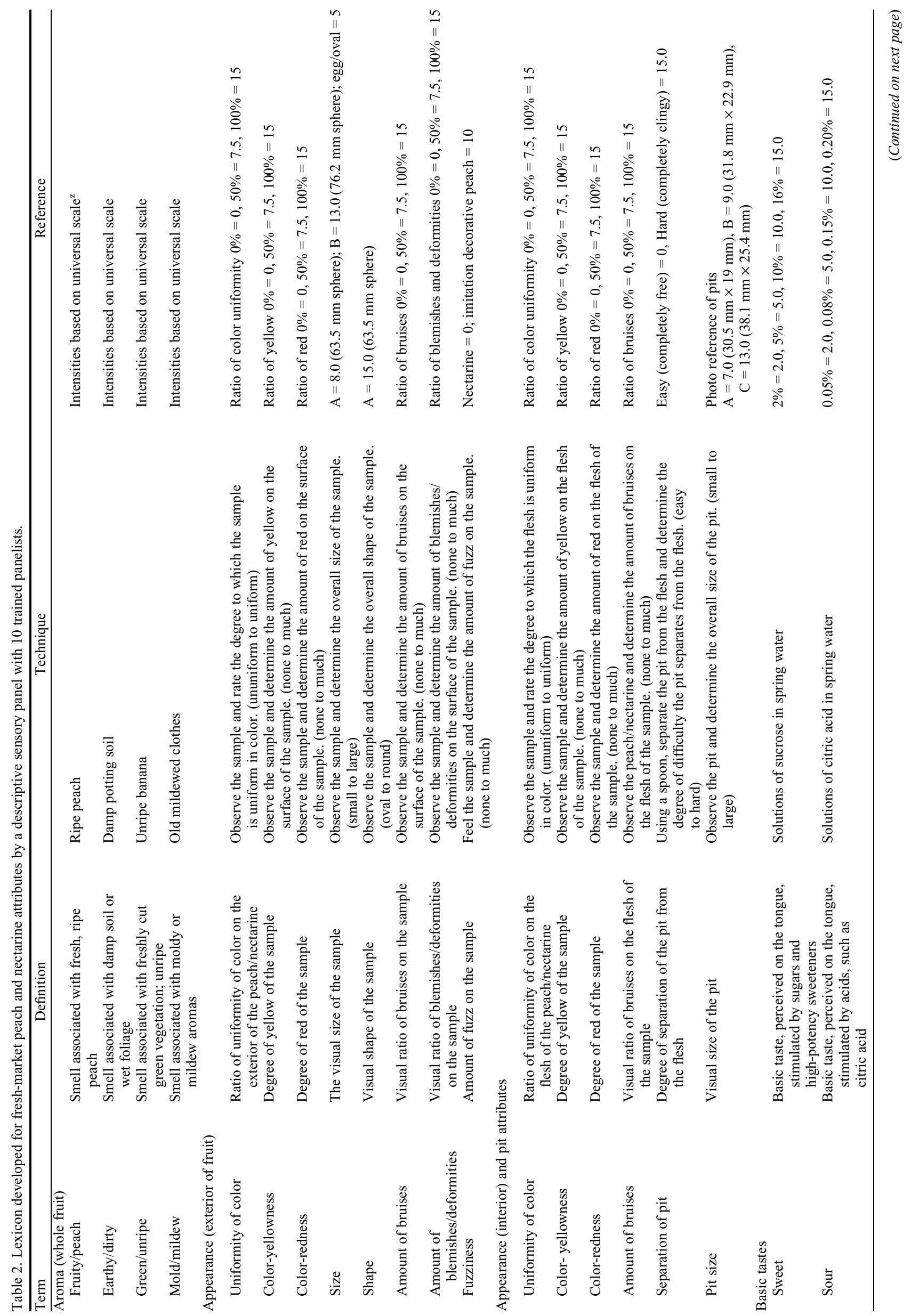




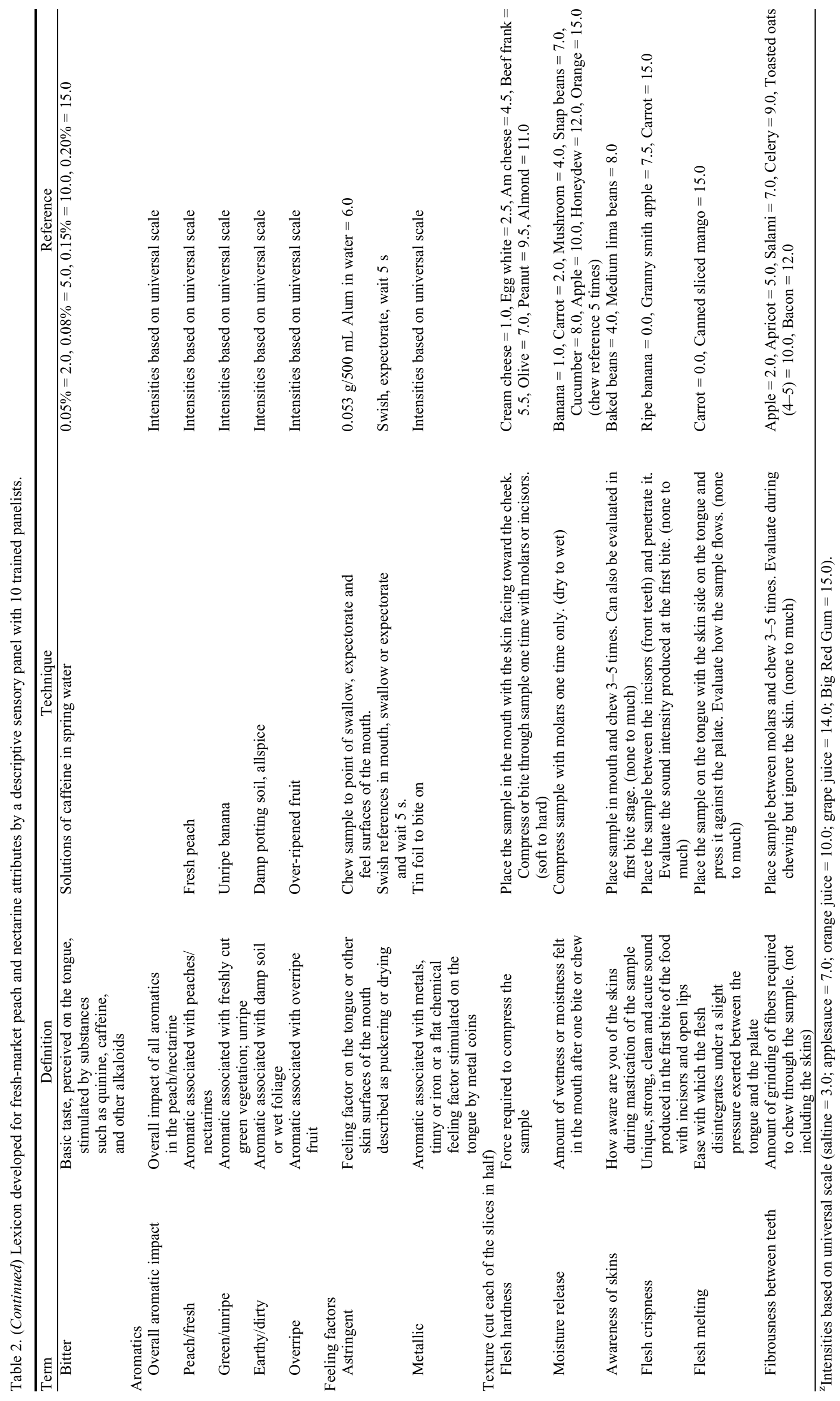




\begin{tabular}{|c|c|c|c|c|c|c|c|c|c|}
\hline Genotype & Fruit wt (g) & Pit wt (g) & Firmness (N) & $\begin{array}{c}\text { Soluble } \\
\text { solids (\%) }\end{array}$ & $\mathrm{pH}$ & $\begin{array}{c}\text { Titratable } \\
\text { acidity }(\%)^{\mathrm{z}}\end{array}$ & $\begin{array}{c}\text { Soluble solids/ } \\
\text { titratable acidity } \\
\text { ratio }\end{array}$ & $\begin{array}{l}\text { Total sugars } \\
(\mathrm{g} / 100 \mathrm{~g})\end{array}$ & $\begin{array}{c}\text { Total organic } \\
\text { acids }(\mathrm{g} / 100 \mathrm{~g})\end{array}$ \\
\hline A-827 & $224.97 a b c^{y}$ & $6.27 \mathrm{bc}$ & $7.77 \mathrm{~b}$ & $7.93 \mathrm{~b}$ & $4.48 \mathrm{ab}$ & $0.24 \mathrm{de}$ & $34.04 \mathrm{bc}$ & $2.45 \mathrm{~b}$ & $0.23 \mathrm{~b}$ \\
\hline A- 850 & $252.33 \mathrm{abc}$ & $6.58 \mathrm{bc}$ & $13.25 \mathrm{~b}$ & $9.87 \mathrm{ab}$ & $4.79 \mathrm{a}$ & $0.16 \mathrm{e}$ & $63.62 \mathrm{a}$ & $2.09 \mathrm{~b}$ & $0.30 \mathrm{~b}$ \\
\hline A-865 & $134.40 \mathrm{c}$ & $5.49 \mathrm{bc}$ & $35.81 \mathrm{a}$ & $14.70 \mathrm{a}$ & $3.30 \mathrm{e}$ & $1.07 \mathrm{a}$ & $14.02 \mathrm{c}$ & $10.36 \mathrm{a}$ & $0.84 \mathrm{a}$ \\
\hline Amoore Sweet & $137.46 \mathrm{c}$ & $4.62 \mathrm{c}$ & $25.31 \mathrm{ab}$ & $8.93 \mathrm{~b}$ & $4.21 \mathrm{bc}$ & $0.36 \mathrm{cde}$ & $24.61 \mathrm{bc}$ & $1.99 \mathrm{~b}$ & $0.14 \mathrm{~b}$ \\
\hline Bowden & $170.62 \mathrm{bc}$ & $9.16 \mathrm{ab}$ & $35.14 \mathrm{a}$ & $8.67 \mathrm{~b}$ & $3.68 \mathrm{de}$ & $0.75 \mathrm{ab}$ & $12.67 \mathrm{c}$ & $5.95 \mathrm{ab}$ & $0.86 \mathrm{a}$ \\
\hline Effie & $201.54 \mathrm{bc}$ & $9.15 \mathrm{ab}$ & $24.70 \mathrm{ab}$ & $11.93 \mathrm{ab}$ & $4.03 \mathrm{~cd}$ & 0.45 bcde & $27.21 \mathrm{bc}$ & $2.93 \mathrm{~b}$ & $0.16 \mathrm{~b}$ \\
\hline Loring & $286.67 \mathrm{ab}$ & $6.27 \mathrm{bc}$ & $17.74 \mathrm{ab}$ & $7.50 \mathrm{~b}$ & $3.66 \mathrm{de}$ & $0.51 \mathrm{bcd}$ & $14.66 \mathrm{c}$ & $2.72 \mathrm{~b}$ & $0.48 \mathrm{ab}$ \\
\hline Souvenirs & $168.15 \mathrm{bc}$ & $4.70 \mathrm{c}$ & $35.18 \mathrm{a}$ & $10.67 \mathrm{ab}$ & $4.67 \mathrm{a}$ & $0.23 \mathrm{de}$ & $48.28 \mathrm{ab}$ & $1.71 \mathrm{~b}$ & $0.11 \mathrm{~b}$ \\
\hline White River & $330.20 \mathrm{a}$ & $11.06 \mathrm{a}$ & $9.55 \mathrm{~b}$ & $10.17 \mathrm{ab}$ & $3.62 \mathrm{de}$ & $0.65 \mathrm{bc}$ & $15.69 \mathrm{c}$ & $6.29 \mathrm{ab}$ & $0.26 \mathrm{~b}$ \\
\hline$P$ value & 0.0003 & 0.0408 & $<0.0001$ & 0.0032 & $<0.0001$ & $<0.0001$ & $<0.0001$ & 0.0025 & $<0.0001$ \\
\hline
\end{tabular}

zTitratable acidity expressed as \% malic acid.

${ }^{\mathrm{y}}$ Means with different letter(s) for each attribute within effects are significantly different $(P<0.05)$ using Tukey's honestly significant difference test.

maturity indices as a way to define the stage of development of the fruit to give a minimum acceptable quality to the consumer, concluding that of the three composition attributes (soluble solids, $\mathrm{pH}$, and titratable acidity), soluble solids was a good indicator of maturity. Crisosto and Crisosto (2005) found that consumer acceptability increased with an increase in soluble solids and preferred soluble solids of high-acid cultivars ranging from $10 \%$ to $12 \%$, and low-acid cultivars ranging from $15 \%$ to $16 \%$. Above those ranges, consumer acceptability plateaued. As defined by Crisosto and Crisosto (2005), high acid genotypes have a titratable acidity ranging from $0.7 \%$ to $0.9 \%$, and low acid genotypes have a titratable acidity ranging from $0.3 \%$ to $0.5 \%$. The high and low acid genotypes in this study were outside of those ranges.

Another key finding of Crisosto and Crisosto (2005) was that consumer acceptance was greatly influenced by the balance of soluble solids/titratable acidity ratio, rather than either attribute alone. However, great differences in consumer acceptance were found for the different acid types, indicating no single value will describe the optimum ripeness parameters of peaches and nectarines. Of the soluble solids/titratable acidity ratio of the nine genotypes in this study, A-850 (63.62) had the highest soluble solids/titratable acidity ratio, whereas 'Bowden' (12.67), A-865 (14.02), 'Loring' (14.66), and 'White River' (15.69) had the lowest (Table 3). As expected, the low acid peaches (A-827, A850, 'Amoore Sweet', and 'Souvenirs') had higher ratios than the high acid fruit (A-865, 'Bowden', 'Loring', and 'White River').

The total sugars (glucose + fructose) and total organic acids (isocitric + malic acid) were significantly different for the genotypes in this study (Table 3). A-865 (10.36 g/100 g) had the highest total sugars and 'Souvenirs' $(1.71 \mathrm{~g} / 100 \mathrm{~g})$ the least. 'Bowden' had the highest total organic acids $(0.86 \mathrm{~g} / 100 \mathrm{~g})$ and 'Souvenirs' $(0.11 \mathrm{~g} / 100 \mathrm{~g})$ the lowest. The primary individual sugars and acids varied by genotype. Glucose and fructose ranged from 0.57 to $5.57 \mathrm{~g} / 100 \mathrm{~g}$ and 1.08 to $4.80 \mathrm{~g} / 100 \mathrm{~g}$, respectively. A-865 had the highest glucose and fructose, 'Souvenirs' had the lowest glucose, and 'Amoore Sweet' had the lowest fructose. In a study by Chinnici et al. (2005), the glucose and fructose concentrations in

Table 4. Skin and flesh color attributes for fresh-market peach and nectarine genotypes, Clarksville, AR (2017).

\begin{tabular}{|c|c|c|c|c|c|}
\hline \multirow[b]{2}{*}{ Genotype } & \multicolumn{2}{|c|}{ Skin } & \multicolumn{3}{|c|}{ Flesh } \\
\hline & $\mathrm{L}^{*}$ & Chroma & $\mathrm{L}^{*}$ & Chroma & Hue \\
\hline A-827 & $51.72{a b^{2}}^{2}$ & $44.52 \mathrm{abc}$ & $70.56 \mathrm{a}$ & $48.63 \mathrm{a}$ & $87.20 \mathrm{ab}$ \\
\hline A- 850 & $56.39 \mathrm{ab}$ & $37.71 \mathrm{bcd}$ & $73.02 \mathrm{a}$ & $16.27 \mathrm{~b}$ & $99.89 \mathrm{a}$ \\
\hline A-865 & $59.51 \mathrm{ab}$ & $31.73 \mathrm{~d}$ & $70.01 \mathrm{a}$ & $20.28 \mathrm{~b}$ & $81.49 \mathrm{ab}$ \\
\hline Amoore Sweet & $49.65 \mathrm{ab}$ & $52.23 \mathrm{a}$ & $65.70 \mathrm{a}$ & $49.68 \mathrm{a}$ & $80.45 \mathrm{ab}$ \\
\hline Bowden & $57.73 \mathrm{ab}$ & $37.37 \mathrm{bcd}$ & $72.42 \mathrm{a}$ & $26.14 \mathrm{~b}$ & $98.22 \mathrm{a}$ \\
\hline Effie & $47.73 \mathrm{ab}$ & $36.13 \mathrm{~cd}$ & $71.15 \mathrm{a}$ & $23.09 \mathrm{~b}$ & $99.08 \mathrm{a}$ \\
\hline Loring & $59.56 \mathrm{a}$ & $47.52 \mathrm{ab}$ & $66.34 \mathrm{ab}$ & $47.50 \mathrm{a}$ & $83.85 \mathrm{ab}$ \\
\hline Souvenirs & $38.38 \mathrm{~b}$ & $37.94 \mathrm{bcd}$ & $55.57 \mathrm{~b}$ & $38.79 \mathrm{a}$ & $56.52 \mathrm{~b}$ \\
\hline White River & $62.52 \mathrm{a}$ & $33.53 \mathrm{~d}$ & $67.09 \mathrm{ab}$ & $19.47 \mathrm{~b}$ & $60.72 \mathrm{~b}$ \\
\hline$P$ value & 0.0205 & $<0.0001$ & 0.0095 & $<0.0001$ & 0.0039 \\
\hline
\end{tabular}

${ }^{\mathrm{z}}$ Genotypes were evaluated in triplicate $(\mathrm{n}=3)$. Means with different letter(s) for each attribute within effects are significantly different $(P<0.05)$ using Tukey's honestly significant difference test.

commercial peach juice was 3.65 to 4.26 $\mathrm{g} / 100 \mathrm{~g}$ and 3.43 to $7.54 \mathrm{~g} / 100 \mathrm{~g}$, respectively. Similarly, they found citric and malic acid concentrations ranging from 0.10 to 0.19 $\mathrm{g} / 100 \mathrm{~g}$ and 0.15 to $0.56 \mathrm{~g} / 100 \mathrm{~g}$, respectively. In this study, the isocitric and malic acid contents of the nine genotypes ranged from 0.06 to $0.59 \mathrm{~g} / 100 \mathrm{~g}$ and 0.03 to 0.66 $\mathrm{g} / 100 \mathrm{~g}$, respectively. These values were similar to or greater than those found by Chinnici et al. (2005). The predominant acid varied by genotype; A-827, 'Bowden', and 'Souvenirs' had predominantly isocitric acid; A-850, A-865, and 'White River' had predominantly malic acid; and 'Effie' and 'Loring' had roughly equal amounts of both acids (data not shown). 'Bowden' had the highest isocitric acid content, and 'Amoore Sweet' had the lowest. A-865 had the highest malic acid content, and 'Souvenirs' had the lowest. In a study by Wang et al. (1993), the malic and citric acid content also varied among peach cultivars.

\section{Sensory attributes at harvest}

Descriptive sensory attributes were evaluated on the nine peaches and nectarines at harvest. Sensory analysis has been shown to explain cultivar characteristics, better than instrumental measurements alone (Delgado et al., 2013). During orientation and training, the 10 trained panelists created a lexicon of descriptive sensory terms using Arkansasgrown peaches and nectarines (Table 2). Within each category, multiple attributes were evaluated.

The panelists evaluated aroma (fruity/ peach, earthy/dirty, green/unripe, and mold/ mildew) of the whole, intact fruit. The panelists detected differences between genotypes in fruity/peach aroma $(2.5-4.3$ on a 15-point scale), but not earthy/dirty, green/ unripe, or mold/mildew, which received low ratings $(\leq 1)$ (Table 5). 'Effie' and 'Loring' had the highest fruity/peach aroma, and A827 had the lowest. In a study by Jordan et al. (1989), a relationship was found between aroma and flavor; however, they concluded that the relationship was not strong enough to influence a consumer to purchase the fruit. In addition, they found that aroma intensified during later stages of senescence. Therefore, because the fruit in this study was evaluated at harvest, the aroma scores may be lower than the consumer would experience in a commercial setting, as the fruit is stored before sale and ripeness aromas might increase during that storage.

The panelists then evaluated the exterior appearance (uniformity of color, coloryellowness, color-redness, size, shape, amount of bruises, amount of blemishes/ deformities, and fuzziness) of the whole, intact fruit (Table 6). Of the eight attributes, the panelists detected differences among the genotypes for all attributes except amount of bruises, which was low ( $\leq 1.6)$. Uniformity of color was evaluated using the ratio of color uniformity, where $0 \%$ was rated 0 and $100 \%$ was scored 15. Uniformity of color ranged from 7.3 to 9.9 , where 'Souvenirs' had the highest uniformity, and A-865 had the lowest. This indicated that A-865 had a fairly equal distribution of yellow and red, whereas 'Souvenirs' had more of one color. Yellowness was evaluated using a ratio of yellow, in 
Table 5. Descriptive sensory aroma, basic taste, aromatic, feeling factor, and texture attributes for fresh-market peach and nectarine genotypes evaluated on a 15point scale $(0=$ less of the attribute; $15=$ more of the attribute in terms of intensity), Clarksville, AR (2017).

\begin{tabular}{|c|c|c|c|c|c|c|c|c|c|c|}
\hline \multirow{2}{*}{ Genotype } & \multirow{2}{*}{$\frac{\text { Aroma }}{\text { Fruity/peach }}$} & \multirow{2}{*}{$\frac{\text { Basic taste }}{\text { Sour }}$} & & & \multirow{2}{*}{$\frac{\text { Feeling factor }}{\text { Astringent }}$} & \multicolumn{5}{|c|}{ Texture } \\
\hline & & & \multicolumn{2}{|c|}{ Aromatics } & & $\begin{array}{c}\text { Flesh } \\
\text { hardness }\end{array}$ & $\begin{array}{l}\text { Moisture } \\
\text { release }\end{array}$ & $\begin{array}{c}\text { Flesh } \\
\text { crispness }\end{array}$ & $\begin{array}{l}\text { Flesh } \\
\text { melting }\end{array}$ & $\begin{array}{l}\text { Fibrousness } \\
\text { between teeth }\end{array}$ \\
\hline $\mathrm{A}-827$ & $2.5 \mathrm{c}^{\mathrm{z}}$ & $2.1 \mathrm{~cd}$ & $3.8 \mathrm{ab}$ & $0.0 \mathrm{c}$ & $6.5 \mathrm{a}$ & $6.8 \mathrm{ab}^{\mathrm{z}}$ & $6.5 \mathrm{ab}$ & $7.1 \mathrm{ab}$ & $2.7 \mathrm{bc}$ & $4.8 \mathrm{ab}$ \\
\hline Amoore Sweet & $4.0 \mathrm{ab}$ & $2.9 \mathrm{abcd}$ & $3.9 \mathrm{a}$ & $0.0 \mathrm{c}$ & $6.1 \mathrm{bc}$ & $7.2 \mathrm{a}$ & $5.1 \mathrm{~b}$ & $7.8 \mathrm{a}$ & $0.8 \mathrm{c}$ & $5.4 \mathrm{a}$ \\
\hline Bowden & $3.7 \mathrm{abc}$ & $4.6 \mathrm{a}$ & $4.0 \mathrm{a}$ & $0.0 \mathrm{c}$ & $6.2 \mathrm{abc}$ & $7.3 \mathrm{a}$ & $4.9 \mathrm{~b}$ & $8.0 \mathrm{a}$ & $0.6 \mathrm{c}$ & $5.5 \mathrm{a}$ \\
\hline Effie & $4.3 \mathrm{a}$ & $3.4 \mathrm{abc}$ & $4.2 \mathrm{a}$ & $0.0 \mathrm{c}$ & $6.2 \mathrm{abc}$ & $7.3 \mathrm{a}$ & $5.4 \mathrm{~b}$ & $7.7 \mathrm{ab}$ & $1.1 \mathrm{c}$ & $5.2 \mathrm{ab}$ \\
\hline White River & $3.6 \mathrm{abc}$ & $3.4 \mathrm{abc}$ & $3.0 \mathrm{~b}$ & $0.8 \mathrm{a}$ & $6.5 \mathrm{ab}$ & $5.4 \mathrm{c}$ & $7.7 \mathrm{a}$ & $5.1 \mathrm{c}$ & $4.6 \mathrm{ab}$ & $4.2 \mathrm{~b}$ \\
\hline$P$ value & 0.0002 & $<0.0001$ & 0.0029 & 0.0123 & 0.0211 & $<0.0001$ & $<0.0001$ & $<0.0001$ & $<0.0001$ & 0.0004 \\
\hline
\end{tabular}

${ }^{\mathrm{z}}$ Genotypes were evaluated in duplicate by 10 trained panelists. Means with different letter(s) for each attribute are significantly different $(P<0.05)$ using Tukey's honestly significant difference test.

Table 6. Descriptive sensory exterior appearance attributes of fresh-market peach and nectarine genotypes evaluated on a 15 -point scale $(0=$ less of the attribute; $15=$ more of the attribute in terms of intensity), Clarksville, AR (2017).

\begin{tabular}{|c|c|c|c|c|c|c|c|}
\hline Genotype & Uniformity of color & Color-yellowness & Color-redness & Size & Shape & $\begin{array}{l}\text { Amount of blemishes/ } \\
\text { deformities }\end{array}$ & Fuzziness \\
\hline A- 850 & $8.2 \mathrm{abc}$ & $4.9 \mathrm{bcd}$ & $8.7 \mathrm{abc}$ & $12.7 \mathrm{a}$ & $11.3 \mathrm{ab}$ & $3.2 \mathrm{a}$ & $8.0 \mathrm{a}$ \\
\hline A- 865 & $7.3 \mathrm{c}$ & $5.6 \mathrm{abc}$ & $8.0 \mathrm{abcd}$ & $8.9 \mathrm{~d}$ & $9.9 \mathrm{ab}$ & $3.6 \mathrm{a}$ & $0.0 \mathrm{~b}$ \\
\hline Bowden & $7.5 \mathrm{c}$ & $6.3 \mathrm{ab}$ & $7.1 \mathrm{~cd}$ & $10.8 \mathrm{bc}$ & $11.1 \mathrm{ab}$ & $3.8 \mathrm{a}$ & $0.5 \mathrm{~b}$ \\
\hline Effie & $7.5 \mathrm{bc}$ & $4.4 \mathrm{~cd}$ & $8.1 \mathrm{abcd}$ & $10.4 \mathrm{~cd}$ & $9.9 \mathrm{ab}$ & $4.1 \mathrm{a}$ & $0.0 \mathrm{~b}$ \\
\hline Loring & $8.3 \mathrm{abc}$ & $6.5 \mathrm{ab}$ & $7.8 \mathrm{bcd}$ & $13.1 \mathrm{a}$ & $11.3 \mathrm{ab}$ & $1.8 \mathrm{~b}$ & $7.8 \mathrm{a}$ \\
\hline$P$ value & $<0.0001$ & $<0.0001$ & $<0.0001$ & $<0.0001$ & 0.0042 & $<0.0001$ & $<0.0001$ \\
\hline
\end{tabular}

${ }^{\mathrm{z}}$ Genotypes were evaluated in duplicate by 10 trained panelists. Means with different letter(s) for each attribute are significantly different $(P<0.05)$ using Tukey's honestly significant difference test.

which $0 \%$ yellow was scored 0 and $100 \%$ yellow was scored 15 . Yellowness of the fruit did not describe intensity of yellow, but rather the ground color (whitish yellow to very yellow depending on genotype). Yellowness ranged from 3.4 to 6.8 where 'Amoore Sweet' was the most yellow. Similar to yellowness, redness was evaluated using a ratio of red in which $0 \%$ red was scored 0 and $100 \%$ red was scored 15 . Redness ranged from 6.3 to 10.0 where 'Souvenirs' was the most red. Using 'Souvenirs' as an example, the high degree of uniformity indicated the skin of the fruit was predominantly one color. Results from the degree of yellowness indicated little yellow, or ground color, and the degree of redness indicated a high degree of red, or blush. Over a 6-year period, 'Souvenirs' reported an average of $90 \%$ blush, the highest of all University of Arkansas peach releases (Clark and Sandefur, 2013).

Size was evaluated using spheres of various diameters as references. A 2.5-inch (6.4 $\mathrm{cm})$ sphere was scored an 8 , whereas a 3 -inch $(7.6 \mathrm{~cm})$ sphere was scored a 13. Size ranged from 8.9 to 13.5 , where 'White River' was the largest, and A-865 was the smallest (Table 6). Shape was evaluated as the degree of roundness of the fruit using a 2.5 -inch $(6.4 \mathrm{~cm})$ sphere to indicate a score of 15 , and an egg to indicate a score of 5. Shape ranged from 9.4 to 11.7, where 'White River' was the roundest, and 'Amoore Sweet' was the least round. Shape has been linked to inadequate chilling or prolonged dormancy, which could lead to a more oblong shape (Wert et al., 2007). However, elongation or a more oval shape can vary between cultivars (Quilot et al., 2004). Although the location (Clarksville, AR) where these genotypes are grown is a high chill environment averaging $1000+$ chill hours annually (Worthington and Clark, 2019), none of the peach and nectarine genotypes in this study have shown signs of inadequate chilling during years of testing at this site. Amount of blemishes/deformities were evaluated as the visual ratio of blemishes on the fruit, in which $0 \%$ would be a score of 0 and $100 \%$ a score of 15. Blemishes/deformities ranged from 1.8 to 4.1, where 'Effie' had the most, and 'Loring' had the least. Fuzziness was evaluated as the amount of fuzz or pubescence on the fruit, with scores ranging from 0.0 to 8.0. The reference for fuzziness was an artificial decorative peach (scored at 10.0) purchased at a local retailer. Most of the nectarines that lack the fuzzy exterior were scored a 0 . Panelists did detect differences in the level of fuzz of the peaches with 'Souvenirs' less fuzzy than the other peaches. Fuzziness of the peaches was indistinguishable among A-827, A-850, 'Loring', and 'White River'.

The panelists detected differences among the genotypes for all six interior appearance and pit attributes (Table 7). Uniformity of color ranged from 8.5 to 13.3 , where 'Bowden' had the highest uniformity of color, and 'White River' had the least. Yellowness ranged from 7.9 to 13.5 , and redness ranged from 0.9 to 5.9, where 'Amoore Sweet' had the highest yellowness, 'White River' had the least yellowness and most redness, and 'Bowden' had the least redness. Amount of bruises ranged from 0.4 to 2.5 , in which 'Loring' had the most bruises and 'Amoore Sweet' the least, although the amount of bruises were low. Nectarines tended to have fewer visible bruises than the peaches. Separation from pit was evaluated as the degree of separation of the pit from the flesh, in which a score of 0 would be easy, and a score of 15 was very difficult (clingy). Separation from pit ranged from 6.9 to 13.9, where 'Amoore Sweet', a clingstone nectarine, scored highest, and A-850, a freestone peach, scored lowest. Pit size ranged from 7.3 to 11.0, where 'White River' had the largest pit, and 'Souvenirs' had the smallest.

Three basic tastes (sweet, sour, and bitter) of the fruit were evaluated. The references for sweet, sour, and bitter were solutions of sucrose in spring water, solutions of citric acid in spring water, and solutions of caffeine in spring water, respectively. Of the three basic tastes, sourness was the only attribute that differed among the genotypes (Table 5). Sourness ranged from 1.6 to 4.6 , where 'Bowden' was the most sour, and A-850 was the least sour (with a $0.05 \%$ solution of citric acid $=2$ and $0.08 \%$ solution $=5$ ). Sweetness of these genotypes ranged from 3.5 to 4.4 (with a $5 \%$ solution of sucrose $=5$ ) and bitterness was less than 1.0 (with a $0.05 \%$ solution of caffeine $=2$ ). It was interesting that the panelists were able to detect differences in the sourness but were not able to detect differences in the sweetness of the fruit 
Table 7. Descriptive sensory interior appearance and pit attributes of the flesh of fresh-market peach and nectarine genotypes evaluated on a 15 -point scale $(0=$ less of the attribute; $15=$ more of the attribute in terms of intensity), Clarksville, AR (2017).

\begin{tabular}{|c|c|c|c|c|c|c|}
\hline Genotype & Uniformity of color & Color-yellowness & Color-redness & Amount of bruises & Separation of pit & Pit size \\
\hline$\overline{A-827}$ & $10.1 \mathrm{~cd}^{\mathrm{z}}$ & $9.8 \mathrm{bc}$ & $4.4 \mathrm{ab}$ & $2.1 \mathrm{abc}$ & $10.8 \mathrm{ab}$ & $8.7 \mathrm{bc}$ \\
\hline A-850 & $13.1 \mathrm{a}$ & $13.0 \mathrm{a}$ & $1.6 \mathrm{~d}$ & $1.9 \mathrm{abcd}$ & $6.9 \mathrm{c}$ & $9.5 \mathrm{ab}$ \\
\hline A-865 & $10.8 \mathrm{bc}$ & $9.6 \mathrm{c}$ & $3.4 \mathrm{bc}$ & 1.1 bcde & $11.9 \mathrm{ab}$ & $7.9 \mathrm{bc}$ \\
\hline Amoore Sweet & $13.2 \mathrm{a}$ & $13.5 \mathrm{a}$ & $1.0 \mathrm{~d}$ & $0.4 \mathrm{e}$ & $13.9 \mathrm{a}$ & $8.3 \mathrm{bc}$ \\
\hline Bowden & $13.3 \mathrm{a}$ & $13.2 \mathrm{a}$ & $0.9 \mathrm{~d}$ & 0.8 cde & $13.1 \mathrm{a}$ & $8.1 \mathrm{bc}$ \\
\hline Effie & $12.7 \mathrm{ab}$ & $12.2 \mathrm{ab}$ & $1.9 \mathrm{~cd}$ & $0.6 \mathrm{de}$ & $13.6 \mathrm{a}$ & $9.4 \mathrm{ab}$ \\
\hline Loring & $10.0 \mathrm{~cd}$ & $10.1 \mathrm{bc}$ & $4.2 \mathrm{ab}$ & $2.5 \mathrm{a}$ & $8.6 \mathrm{bc}$ & $10.9 \mathrm{a}$ \\
\hline Souvenirs & $9.9 \mathrm{~cd}$ & $9.8 \mathrm{bc}$ & $4.4 \mathrm{ab}$ & $1.0 \mathrm{cde}$ & $11.8 \mathrm{ab}$ & $7.3 \mathrm{c}$ \\
\hline White River & $8.5 \mathrm{~d}$ & $7.9 \mathrm{c}$ & $5.9 \mathrm{a}$ & $2.3 \mathrm{ab}$ & $9.5 \mathrm{bc}$ & $11.0 \mathrm{a}$ \\
\hline$P$ value & $<0.0001$ & $<0.0001$ & $<0.0001$ & $<0.0001$ & $<0.0001$ & $<0.0001$ \\
\hline
\end{tabular}

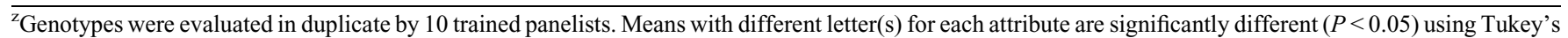
honestly significant difference test.

when the soluble solids ranged from $7.5 \%$ to $14.7 \%$. Crisosto and Crisosto (2005) found that consumer acceptance was closely related to soluble solids content, but maximum consumer acceptance depended on the cultivar. Because the fruit had different acid types (low, medium, and high), the perception of sweetness could be masked.

The aromatic category, which included the aromas/flavors evaluated through retronasal olfaction (while eating the fruit), had five attributes (overall aromatic impact, peach/fresh, green/unripe, earthy/dirty, and overripe). Of the five attributes, green/unripe and overripe were significantly different for the nine genotypes (Table 5). The average overall aromatic impact, peach/fresh aromatics and earthy/dirty aromatics, were 5.9, 1.6 , and 4.3 , respectively. Green/unripe aromatics ranged from 3.0 to 4.3 , with A-850, 'Loring', and 'White River' having the least green/unripe, and A-865 the most. Overripe aromatic attributes were low $(0.0-0.8)$. 'White River' had the highest overripe aromatics, and A-827, 'Amoore Sweet', 'Bowden', 'Effie', and 'Souvenirs' were the least overripe with scores of 0.0 .

Two attributes were evaluated for feeling factors (mouthfeel), astringent and metallic, and the panelists only detected a significant difference in astringency among the nine genotypes (Table 5). Astringency ranged from 5.9 to 6.5 , where A-827 and 'White River' were the most astringent, and 'Souvenirs' was the least. Metallic feeling factors were $\leq 0.8$ for these genotypes.

Texture (flesh hardness, moisture release, awareness of skins, flesh crispness, flesh melting, and fibrousness between teeth) of the fruit was evaluated (Table 5). Panelists detected differences among the genotypes for all attributes except awareness of skins. Flesh hardness was evaluated as the force required to compress the sample between molars. References ranged from cream cheese $=1$ to an almond $=11$. Flesh hardness ranged from 5.2 to 7.5, where 'Souvenirs' (slow melting flesh) had the hardest flesh and 'Loring' (melting flesh) was the least hard (beef frank $=5$ and olive $=7$ for the references). Delgado et al. (2013) found that certain groups of consumers (males) preferred more firm/crunchy cultivars; however, texture was not a primary driver for consumer liking. Before descriptive sensory analysis, Delgado et al. (2013) ripened the fruit postharvest to a "ready to eat" firmness range as established by Crisosto and Crisosto (2005), which could minimize the variation in firmness. However, different flesh types ripen differently during storage, and storage can impact the texture of the fruit as compared with fruit that was ripened on the tree. Moisture release was evaluated as the amount of wetness in the mouth after one bite or chew. References ranged from a banana (1) to an orange (15). Moisture release ranged from 4.9 to 7.8 , where 'Loring' had the most moisture release, and 'Bowden' had the least $($ mushroom $=4$ and snap pea $=8)$. Awareness of skins was evaluated as the awareness of the skins during three to five bites. References ranged from baked beans $=4$ to medium lima beans $=8$. Awareness of skins ranged from 6.6 to 7.5. Flesh crispness was evaluated as the unique, strong, clean, and acute sound produced in the first bite of the food with incisors and open lips. References ranged from a ripe banana $=0$ to a carrot $=15$. Flesh crispness ranged from 4.8 to 8.0 , where 'Souvenirs' (slow-melting flesh) and 'Bowden' (nonmelting flesh) were most crisp and 'Loring' (melting flesh) the least. Flesh melting was evaluated as the ease with which the flesh disintegrates under a slight pressure exerted between the tongue and the palate. References ranged from a carrot $=0$ to a slice of canned mango $=15$. Flesh melting ranged from 0.6 to 6.0, where 'Loring' (melting flesh) had the greatest flesh melting, and 'Bowden' (nonmelting flesh) had the least. Fibrousness between teeth was evaluated as the amount of grinding of fibers required to chew through the sample in three to five bites (references ranged from an apple $=2$ to bacon $=12$ ). Fibrousness ranged from 4.2 to 5.5 , where 'Bowden' (nonmelting flesh) had the greatest fibrousness and 'White River' (melting flesh) the least. The melting flesh fruit tended to have lower flesh hardness, flesh crispness, and fibrousness between teeth as compared with the slow-melting and nonmelting fruit.

\section{Correlations between physicochemical and sensory at harvest}

A multivariate pairwise analysis was carried out to identify significant correlations between the descriptive sensory attributes and physicochemical attributes. Of all of the physicochemical attributes, firmness had the most significant correlations with the descriptive sensory attributes. Firmness was correlated with exterior appearance (size and fuzziness), interior appearance (amount of bruises and pit size), basic taste (sourness), aromatics (green/unripe), and texture (flesh hardness, moisture release, flesh crispness, and fibrousness between teeth). Firmness was negatively correlated with fruit size $(r=-0.81)$, fuzziness $(r=-0.70)$, amount of bruises on the flesh $(r=-0.75)$, pit size $(r=-0.72)$, and moisture release $(r=-0.77)$, and positively correlated with sourness $(r=0.68)$, green/unripe aromatics $(r=0.72)$, flesh hardness $(r=0.70)$, flesh crispness $(r=0.69)$, and fibrousness between the teeth $(r=0.84)$. This indicates the firmer the fruit measured analytically, the smaller the fruit, the smaller the pit, the more green/unripe aromatic, sour, hard, and crisp the flesh, and the less moisture release and bruising/pitting of the flesh. Because pit adherence and flesh type (melting/nonmelting) are controlled by the same genetic locus, there are more clingstone, nonmelting flesh nectarines than peaches. In addition, the University of Arkansas fruit breeding program has focused on breeding low-acid peach/nectarines. Therefore, correlations between firmness with size, acidity, and fuzz are artifacts of the genotypes available in the University of Arkansas program.

Fruit weight also had several significant correlations with descriptive sensory attributes. Fruit weight was positively correlated with exterior appearance (fruit size), interior appearance (pit size), aromatics (overripe), and texture (moisture release). Fruit weight was positively correlated with fruit size ( $r=$ $0.68)$, pit size $(r=0.75)$, overripe aromatics $(r=0.67)$, and moisture release $(r=0.69)$. Bigger fruit tended to be more aromatic and moist than smaller fruit.

The $\mathrm{pH}(r=-0.82)$, titratable acidity $(r=$ 0.89 ), and soluble solids/titratable acidity ratio $(r=-0.77)$ were correlated to the sourness basic taste. The fruit that was perceived as the least sour had a higher $\mathrm{pH}$ and soluble solids/titratable acidity ratio and lower titratable acidity. There were no 


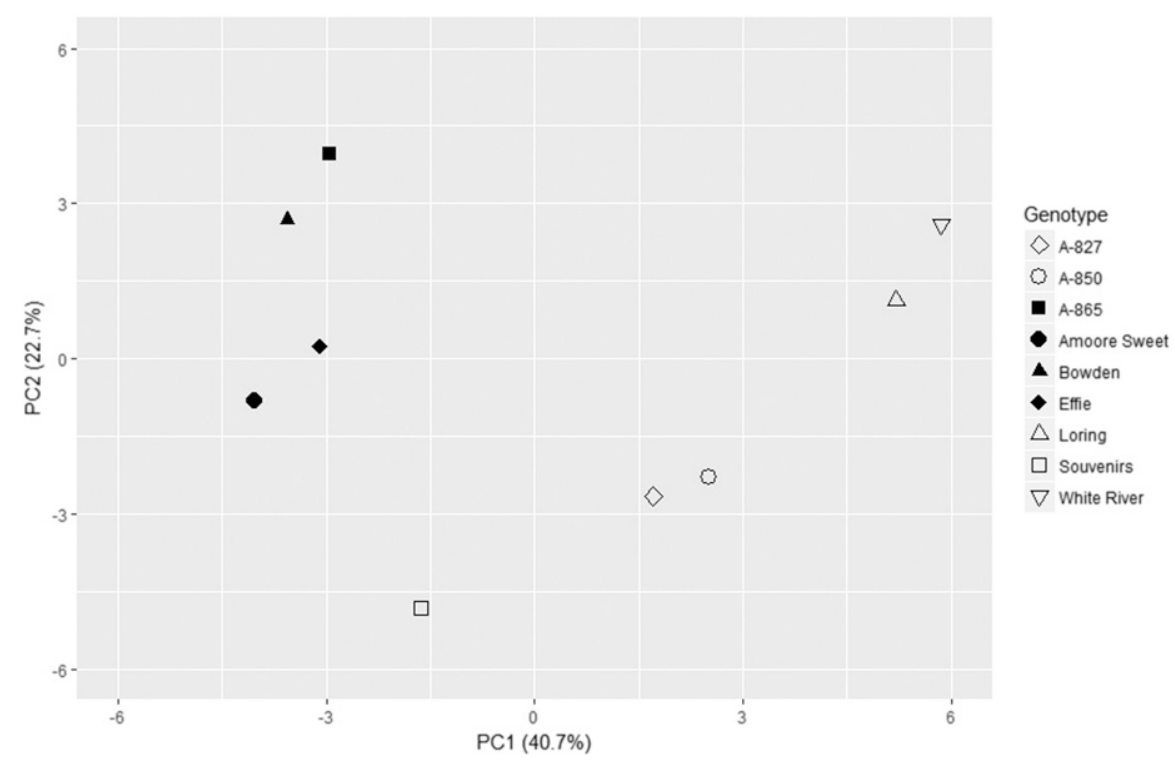

Fig. 1. Principal component (PC) analysis of physicochemical and descriptive sensory attributes of freshmarket peach and nectarine genotypes. Nectarines are indicated with shaded symbols, and peaches are indicated with hollow symbols.

correlations found for soluble solids, total or individual organic acids, and sugars.

To further understand correlations between descriptive sensory and physicochemical attributes, principal component analysis was used to segregate genotypes into different groups (Fig. 1). The perception of physicochemical and descriptive sensory attributes was reduced to two principal components that explained $63.4 \%$ of data variance. Principal component $1(40.7 \%)$ and principal component $2(22.7 \%)$ corresponded to texture and acidity of the fruit, respectively. The nonmelting flesh ('Amoore Sweet', 'Bowden', and 'Effie') and two slow-melting (A-865 and 'Souvenirs') genotypes formed one cluster to the left, whereas slow-melting genotype (A-827) and the melting genotype (A-850) were clustered in the middle, and the two other melting-fleshed genotypes ('Loring' and 'White River') grouped together far to the right. Interestingly, all the nectarine genotypes were clustered to the left. The University of Arkansas fruit breeding program has specifically focused on the development of clingstone, nonmelting flesh nectarines with superior postharvest storage potential (Worthington and Clark, 2019). In nectarines, the clingstone pit is not considered a negative attribute because consumers are more likely to bite directly into whole fruit, unlike peaches, which are often peeled and sliced before eating. The wide distribution of slow-melting genotypes across the $\mathrm{x}$-axis indicated that there was substantial variation in quantitative firmness within that broad texture class. This is supported by analytical measurements of firmness; the firmest (A-865) and least firm (A-827) genotypes were both categorized as slow-melting types. The second principal component corresponded to acidity, with the high-acid types (A-865, 'Bowden', 'Loring', and 'White River') above the $\mathrm{x}$-axis and the low-acid types (A-827,
Blaauw, B., P. Brannen, B. Bellinger, D. Lockwood, and D. Ritchie. 2018. Southeastern peach, nectarine, and plum pest management and culture guide. Univ. Ga. Coop. Ext. Serv. Bul.

Contador, L., M. Díaz, E. Hernández, P. Shinya, and R. Infante. 2017. The relationship between instrumental tests and sensory determinations of peach and nectarine texture. Eur. J. Hort. Sci. 81:189-196.

Chinnici, F., U. Spinabelli, C. Riponi, and A. Amati. 2005. Optimization of the determination of organic acids and sugars in fruit juices by ion-exclusion liquid chromatography. J. Food Compos. Anal. 18:121-130.

Commission Internationale de l'Eclairage (CIE). 1986. Colorimetry. 2nd ed. Publication CIE No. 15.2. Commission Internationale de l'Eclairage, Vienna.

Clark, J. and J. Moore. 2003. 'White river' peach. HortScience 38:1257-1259.

Clark, J.R. and P.J. Sandefur. 2013. 'Souvenirs' peach. HortScience 48:800-803.

Crisosto, C.H. 1994. Stone fruit maturity indices: A descriptive review. Postharvest News Info $5: 65 \mathrm{~N}-68 \mathrm{~N}$.

Crisosto, C.H. and G.M. Crisosto. 2005. Relationship between ripe soluble solids concentration (RSSC) and consumer acceptance of high and low acid melting flesh peach and nectarine (Prunus persica (L.) Batsch) cultivars. Postharvest Biol. Technol. 38(3):239-246.

Delgado, C., G.M. Crisosto, H. Heymann, and C.H. Crisosto. 2013. Determining the primary drivers of liking to predict consumers' acceptance of fresh nectarines and peaches. J. Food Sci. 78:S605-S614.

Ghiani, A., N. Negrini, S. Morgutti, F. Baldin, F.F. Nocito, A. Spinardi, I. Mignani, D. Bassi, and M. Cocucci. 2011. Melting of 'Big Top' nectarine fruit: Some physiological, biochemical, and molecular aspects. J. Amer. Soc. Hort. Sci. 136:61-68.

Jordan, J.L., R.L. Shewfelt, J.C. Garner, and J.N. Variyam. 1989. Estimating the value of internal quality aspects to consumers. In Wkshp. Measuring Consumer Perception Internal Prod. Qual. 259:139-144.

Ripeness and harvest parameters, such as texture and appearance, were well described by the analytical measurements for composition and firmness, with firmness having the most correlations to descriptive sensory attributes. At least $69 \%$ of the variation in sensory flesh hardness, moisture release, flesh crispness, and fibrousness between teeth, could be explained by firmness measured analytically. Of the composition attributes, $\geq 77 \%$ of the sour taste perceived by the descriptive sensory panel could be explained by $\mathrm{pH}$, titratable acidity, or soluble solids/titratable acidity ratio. Significant correlations among descriptive sensory appearance, basic tastes, aromatics, and texture attributes with physicochemical attributes can provide an indication of ripeness and marketability parameters for peaches and nectarines. These descriptive attributes are quality factors that impact consumer purchases and perception of fresh-market peaches and nectarines.

\section{Literature Cited}

Belisle, C., U. Phan, K. Adhikari, and D. Chavez. 2017. Peaches in Georgia: Finding out what consumers want. HortScience 52:S21.

Bible, B.B. and S. Singha. 1993. Canopy position influences CIELAB coordinates of peach color. HortScience 28:992-993.

Karakurt, Y., D.J. Huber, and W.B. Sherman. 2000. Quality characteristics of melting and nonmelting flesh peach genotypes. J. Sci. Food Agr. 80:1848-1853.

McGuire, R.G. 1992. Reporting of objective color measurements. HortScience 27:1254-1255.

Ramina, A., P. Tonutti, and B. McGlasson. 2008. Ripening, nutrition, and postharvest physiology, p. 550-574. In: B.R. Layne and D. Bassi (eds.). The peach: Botany production and uses. CAB International, London, UK.

Quilot, B., J. Kervella, and M. Génard. 2004. Shape, mass and dry matter content of peaches of varieties with different domestication levels. Scientia Hort. 99:387-393.

Rahmati, M., G. Vercambre, G. Davarynejad, M. Bannayan, M. Azizi, and M. Génard. 2015. Water scarcity conditions affect peach fruit size and polyphenol contents more severely than other fruit quality traits: Water scarcity conditions, peach fruit growth and composition. J. Sci. Food Agr. 95:1055-1065.

Segantini, D.M., R.T. Threlfall, J.R. Clark, L.R. Howard, and C.R. Brownmiller. 2018. Physiochemical changes in floricane and primocane blackberries harvested from primocane genotypes. HortScience 53:9-15.

Shinya, P., L. Contador, S. Predieri, P. Rubio, and R. Infante. 2013. Peach ripening: Segregation at harvest and postharvest flesh softening. Postharvest Biol. Technol. $86: 472-478$.

HortScience Vol. 54(2) February 2019 
Tanou, G., I.S. Minas, F. Scossa, M. Belghazi, A. Xanthopoulou, I. Ganopoulos, P. Madesis, A. Fernie, and A. Molassiotis. 2017. Exploring priming responses involved in peach fruit acclimation to cold stress. Scientific Rpt. 7 (11358):1-14.

U.S. Department of Agriculture (USDA). 2015. Arkansas fruit production report. Washington, DC.
Walker, T., J. Morris, R. Threlfall, and G. Main. 2003. Analysis of wine components in Cynthiana and Syrah wines. J. Agr. Food Chem. 51:1543-1547.

Wang, T., A.R. Gonzalez, E.E. Gbur, and J.M. Aselage. 1993. Organic acid changes during ripening of processing peaches. J. Food Sci. 58:631-632.
Wert, T.W., J.G. Williamson, J.X. Chaparro, E.P. Miller, and R.E. Rouse. 2007. The influence of climate on fruit shape of four low-chill peach cultivars. HortScience 42:1589-1591.

Worthington, M. and J.R. Clark. 2018. 'Effie' nectarine. HortScience 53:897-901.

Worthington, M. and J.R. Clark. 2019. Peach breeding at the University of Arkansas. Acta Hort. In press. 